\title{
THE URINARY EXCRETION OF RADIOIODINE IN VARIOUS THYROID STATES
}

\author{
BY F. RAYMOND KEATING, JR., MARSCHELLE H. POWER, JOSEPH BERKSON, \\ AND SAMUEL F. HAINES \\ (From the Divisions of Medicine, Biochemistry, and Biometry and Medical Statistics, Mayo \\ Clinic, Ròchester, Minnesota)
}

(Received for publication June 23, 1947)

Radioiodine and natural iodine are chemically and physiologically identical, providing the former is present in quantities so small as to be without biologic effects due to radiation per se. A minute quantity of radioiodine may be used to trace, by its radioactivity, the course of a given quantity of iodine through various chemical and biologic reactions. Hertz $(1,2)$ was the first to call attention to the unique possibilities of this method in the study of thyroid function. Hamilton and Soley (12) were the first to apply it to the clinical investigation of the human thyroid. Radioiodine tracers have subsequently been utilized in many studies dealing with the thyroid of laboratory animals, in vitro experiments and clinical investigations. The method has been applied to the study of the biosynthesis of thyroid hormone (1, 3 to 9 ), the action of thyrotrophic hormones $(4,10)$, the action of goitrogens $(5,11)$ and of other factors influencing the function of the thyroid (6), the functional activity of various thyroid tumors and a number of other problems.

It is possible that radioiodine may prove most useful in the study of thyroid function in man. To date, relatively few definitive clinical studies employing this technique have been published. The first was that of Hamilton and Soley (12), who compared the collection by the thyroid of iodine labeled with radioiodine and its excretion in the urine and feces in normal subjects and in patients having various thyroid disorders. Radioiodine in the thyroid was measured directly by the recording of its gamma radiation by means of a Geiger-Müller counter placed over the trachea and in some instances by analysis of surgically removed specimens of thyroid tissue. It was found that an orally administered dose of labeled iodine was absorbed very rapidly and could be detected in the thyroid within 20 minutes. Normal subjects excreted 74 to 89 per cent of the dose in the urine during a period of 5 days, 53 to 81 per cent appearing during the first 24 hours. Two myxedematous patients excreted 91 and 94 per cent, respectively, in the urine during 5 days but at a slower rate than did the normals. Patients who had hyperthyroidism excreted as much in the urine as did the normals. This finding may have been due to the fact that most of the patients had received strong solution of iodine (Lugol's solution) and in part to the very large amount of iodide (14 mgm.) which was administered as a labeled dose. Fecal excretion was variable but averaged only about 1 per cent of the dose.

In another series of in vivo measurements employing the same dose of iodide, Hamilton and Soley (13) recorded characteristic collection curves for various thyroid states. The curve typical of normal thyroids was a smooth curve which leveled off to a flat plateau in 2 days. Iodine collection by thyroids of hyperthyroid patients was greater and much more rapid than in normal thyroids. It rose to a peak within 4 to 8 hours and thereafter decreased almost as rapidly to a plateau lower than that of the normal thyroids. This curious phenomenon was also observed in 2 children who had goiters and hypothyroidism. When a dose of 0.1 microgram of sodium iodide was given instead of $14 \mathrm{mgm}$. such rapid loss of radioiodine from the thyroid was not observed (14).

Hertz, Roberts and Salter (3) studied 22 patients who had exophthalmic goiter and compared these with 2 normal subjects. The quantity of radioactivity was measured in the urine; that in the thyroid was measured in situ by applying a Geiger-Müller counter to the neck. Thyroid tissue was obtained in some cases following thyroidectomy. This was fractionated into diiodotyrosinelike and thyroxine-like fractions, which were also analyzed for radioactivity. The collection by thyroids in untreated exophthalmic goiter averaged 
80 per cent if the accompanying dose of sodium iodide was small ; when the latter exceeded $2 \mathrm{mgm}$. the uptake of radioiodine was smaller. Previous treatment with iodine reduced the quantity collected. The proportion of radioiodine which appeared in the thyroxine-like faction of thyroid tissue varied directly with the time intervening between the administration of the tracer and thyroidectomy.

Rawson and his associates $(15,16)$ studied the urinary excretion of radioiodine in a series of patients with various thyroid states. A patient who had a very large hyperplastic goiter resulting from treatment with potassium thiocyanate excreted only 24 per cent of a tracer dose of radioiodine, whereas a patient who had a similar goiter induced by administration of thiouracil excreted all of the tracer dose. The effect of thiouracil was also studied in a series of patients who had exophthalmic goiter and who were prepared for operation with this drug. The major part of the radioiodine appeared in the urine and very little was found to be in the thyroid. In 5 normal subjects, a total of 80 per cent of the dose appeared in the urine. A series of untreated thyrotoxic patients excreted an average of 16 per cent of the dose in the urine.

Leiter, Seidlin, Marinelli and Baumann (8) have studied the behavior of radioiodine tracers in 2 patients who had hyperfunctioning and metastatic thyroid adenocarcinomas. Both subjects excreted radioiodine in a manner comparable to that observed in cases of exophthalmic goiter. In one case thiouracil effectively reduced collection by the thyroid and in the other, in which the thyroid gland had previously been totally ablated, it proved equally effective in preventing collection of radioiodine by the metastatic thyroid tissue (17).

Leblond, Fertman, Puppel and Curtis (7) studied the form in which iodine is stored in the thyroid in cases of goiter. They found that less than 10 per cent of the quantity collected by the thyroid remained in the form of iodide; the rest was converted to diiodotyrosine or thyroxine. Comparable observations had been made earlier by Hamilton and Soley and their associates (14) in 2 cases of goiter with hypothyroidism.

All of the clinical reports which have appeared have dealt with the proportion of a given dose collected by the thyroid or excreted in the urine, or with the chemical form in which it was stored or secreted by the thyroid. No attempt has been made, thus far, to investigate the rates at which collection, excretion or secretion of iodine occurs. The collection curves reported by Hamilton and Soley are an exception in that the characteristic forms of these curves imply important differences in the dynamics involved although the differences noted were not expressed quantitatively.

The present study was undertaken to investigate the dynamics of iodine metabolism by the tracer method, and to determine, if possible, the rate at which radioiodine is collected by the thyroid, disappears from the blood and is excreted in the urine. The study was undertaken in the hope that this approach might provide the tracer method with greater precision when applied to various aspects of thyroid function in man.

The data to be presented concern chiefly the urinary excretion of radioiodine. Subsequent studies will deal with the concentration of radioiodine in blood and its collection and secretion by the thyroid as measured in vivo. Urinary measurements possess the disadvantage of not being directly concerned with thyroid function. There are, however, 2 reasons for directing attention first to urinary measurements: 1 . The urine is the principal route for the disposal of an ingested dose of iodine in euthyroid or hypothyroid subjects. 2. The analysis of radioiodine in urine is technically much simpler and more accurate than its measurement in blood samples and much more accurate than present methods for measuring radioactivity in vivo.

\section{METHODS}

Iodine of mass 131 having a half life of 8.0 days was obtained from the Clinton Laboratories, where it had been prepared by the bombardment of metallic tellurium with slow neutrons in the chain-reacting pile. The isotope was supplied in solution as carrier-free iodide, with minute amounts of tellurium, sulfates and oxalates as contaminants. The solution was adjusted to $\mathrm{pH} 8.0$, calcium chloride was added to precipitate oxalate, sodium iodide solution was added as carrier and the volume was adjusted so that $1.0 \mathrm{cc}$. contained 5.0 micrograms of sodium iodide and represented 500 microcuries as calculated from the stated activity of the sample as received. The usual tracer dose was 100 microcuries of $I^{131}$ with a 
total of 100 micrograms of sodium iodide as carrier. ${ }^{1}$ In the earlier studies, the tracer doses were given in the morning after breakfast. Later they were given while the subject was fasting because it was found that food appeared to delay absorption appreciably.

Tracers usually were given to patients as outpatients. Instructions regarding the exact collection of specimens of urine were given with great care. They were first reviewed with the patient by the physician, repeated by the technician at the time the tracer was given and emphasized by means of a printed sheet on which the procedure for collection of urine was explicitly prescribed. If after diligent questioning at the time when specimens were returned, an error in collection of specimens was discovered, the data were discarded. In most cases the urine was collected every 6 hours for the first 24 hours and in 24-hour samples thereafter for 2 more days or in some instances for a longer period. In certain cases, especially in those of hyperthyroidism, the collections during the first few hours were made at 1- or 2- hour intervals. With regard to precision of collections of urine, a very satisfactory degree of cooperation has been achieved.

The urine was collected in glass bottles to which had been added sodium hydroxide ( 3 cc. of 2.5 normal solution) and sodium iodide ( $1 \mathrm{mgm}$.) as carrier. The specimens were carefully measured and $0.2 \mathrm{cc}$. was pipetted by means of a syringe pipette onto a copper planchette. Silver nitrate $(0.1 \mathrm{mgm}$. silver in $0.1 \mathrm{cc}$.) was added to the drop on the planchette. If the sample was not properly centered on the planchette it was discarded and another was prepared. The specimen was then evaporated to dryness and counted at once with a Victoreen thin mica window beta-ray counter. The number of counts taken varied with the strength of the sample but, whenever possible, sufficient counts were made to keep the counting errors to within 2 to 5 per cent. All counts were made on duplicate samples. When these did not check closely the analysis was repeated on another pair of duplicates. The results were compared with a standard made from the same shipment of $I^{131}$ as the tracer given the patient and were counted in the same manner and at the same time.

\section{MATERIAL}

Four groups of patients were studied. Group 1 included 4 normal men varying in age from 30 to 46 years, who served as controls. Group 2 consisted of 10 euthyroid patients who were given tracers because of the presence of papillary adenocarcinoma of the thyroid, graded 1 on a basis of 1 to 4 (Broders' method). So far as thyroid or renal function was concerned, these

\footnotetext{
1 Measurements made of aliquots of our samples in the laboratory of Dr. R. D. Evans, Massachusetts Intitute of Technology, indicated that the dose used closely approximated 200 microcuries, in terms of the standards of that laboratory. No attempt is made in this paper to discuss the problem of measurements of radioactivity indicated by this divergence of measurements.
}

patients were essentially normal. Group 3 included 6 patients who had myxedema and in whom in vivo measurements failed to disclose any measurable collection of radioiodine by the thyroid. In 2 of the 6 cases the myxedema was adequately controlled by administration of desiccated thyroid at the time of this study. The remaining 4 patients were untreated at the time of this study: Group 4 included 16 patients who had uncomplicated, untreated exophthalmic goiter. None of these patients had received iodine before the study.

\section{RESULTS}

Curves showing the cumulative urinary excretion of radioiodine by the subjects in the 4 groups mentioned are shown in Figures 1, 2, 3 and 4, respectively. The rate of excretion in the first 2 groups-the 4 normal men and the 10 euthyroid patients-varies somewhat but the curves are obviously exponential in form and each approaches a plateau in about 48 hours. The shape of the curves is strikingly similar to that of the curves constructed by Hamilton and Soley (13) from data obtained by in vivo measurement of radioactivity over normal thyroids after administration of radioiodine.

The rate of excretion of radioiodine by the myxedematous subjects is slower initially than that observed in the first 2 groups but persists much longer. A plateau may not be attained until after 4 days or more. Eventually, however, these subjects excrete in the urine much more of the administered dose of radioiodine than do the normal or euthyroid subjects.

The excretion of radioiodine by the patients who had untreated exophthalmic goiter exhibited a great deal of variation. This may not be surprising, since the severity of hyperthyroidism and the quantity of thyroid tissue present, as well as basal metabolic rates (range +8 to +82 per cent), varied greatly. Nevertheless the excretion rates of all but 2 of this group were well below the mean for normal persons. The 3 cases with highest excretion rates in this group are of particular interest because, although their response resembled that of the normals, they represent relatively severe exophthalmic goiter with basal metabolic rates of $+58,+61$ and +46 per cent, respectively. The diagnosis was confirmed at operation in each instance. The excretion of radioiodine by the remaining subjects in this group was significantly less than in any of the other groups and the 


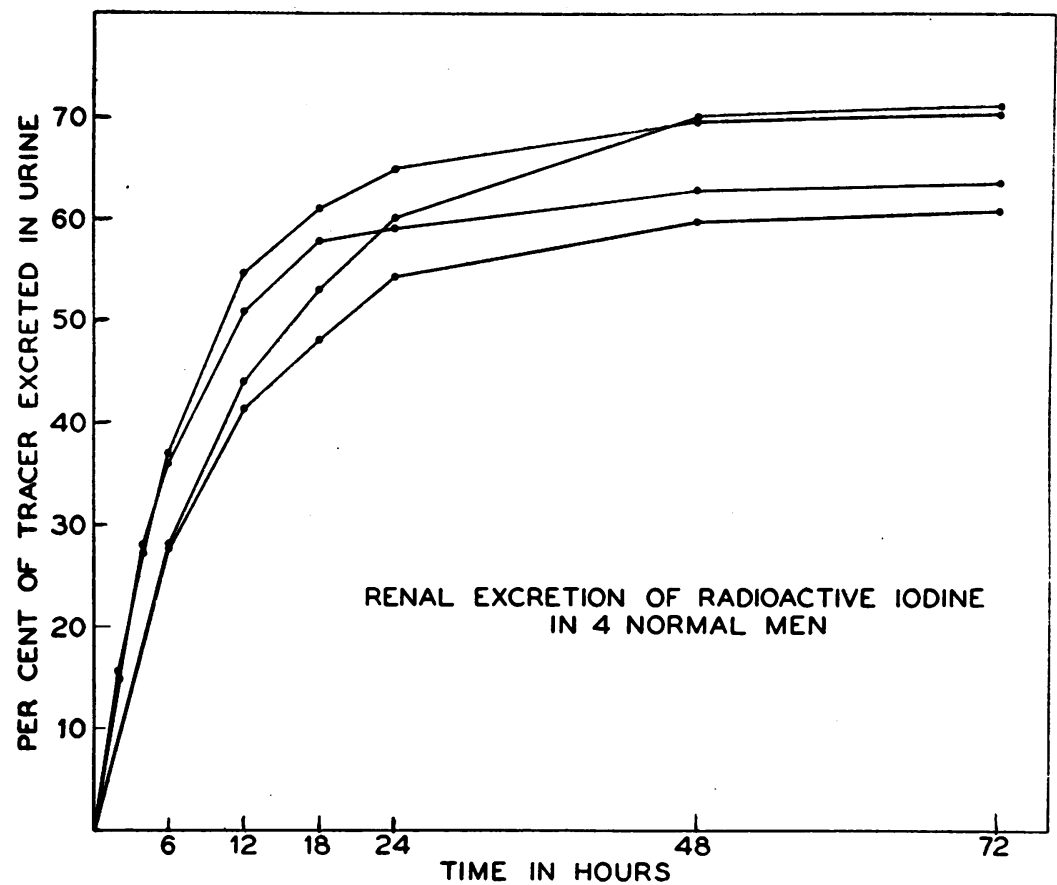

Fig. 1. Urinary Excretion of Radiotodine in 4 Normal Men The form of the curves suggests an exponential function.

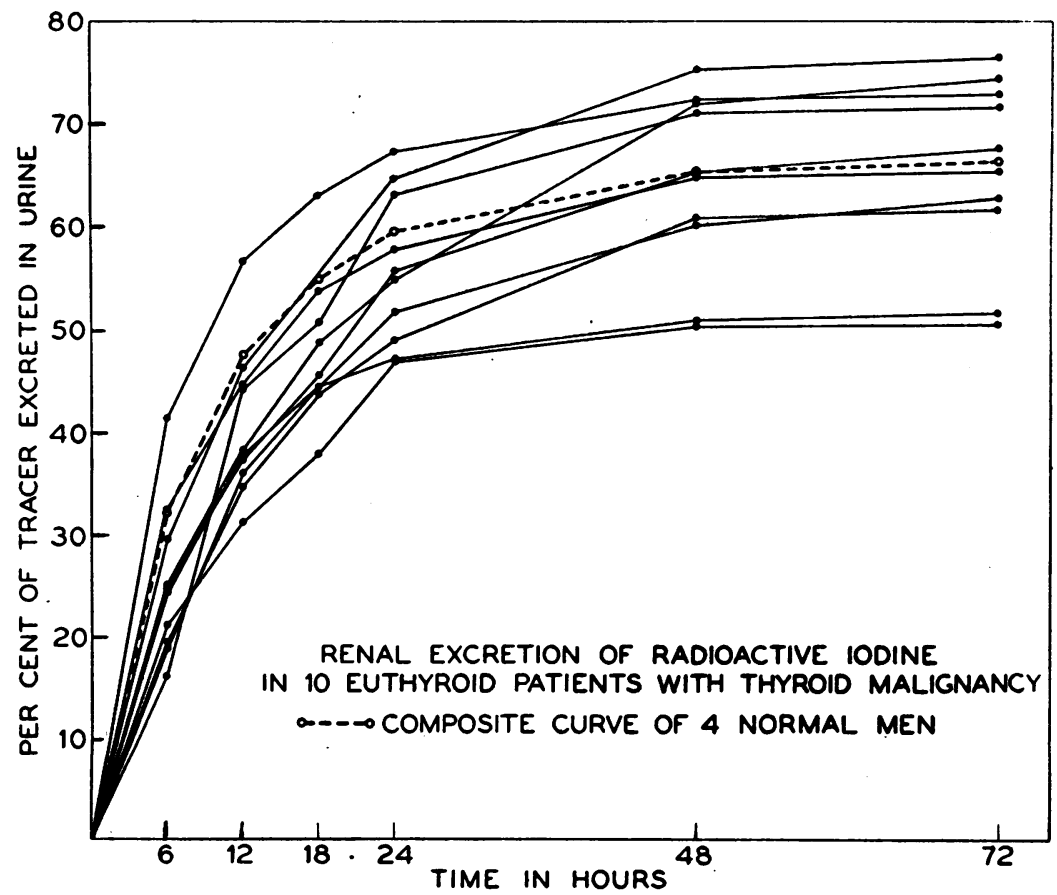

Fig. 2. Urinary Excretion of Radioiodine in 10 Euthyroid Patients Who Had Low-grade Thyroid Malignant Lesions

The composite curve of the normal men is included for comparison. Individual curves vary not only in the plateau which is reached but also in the time required to reach it. 


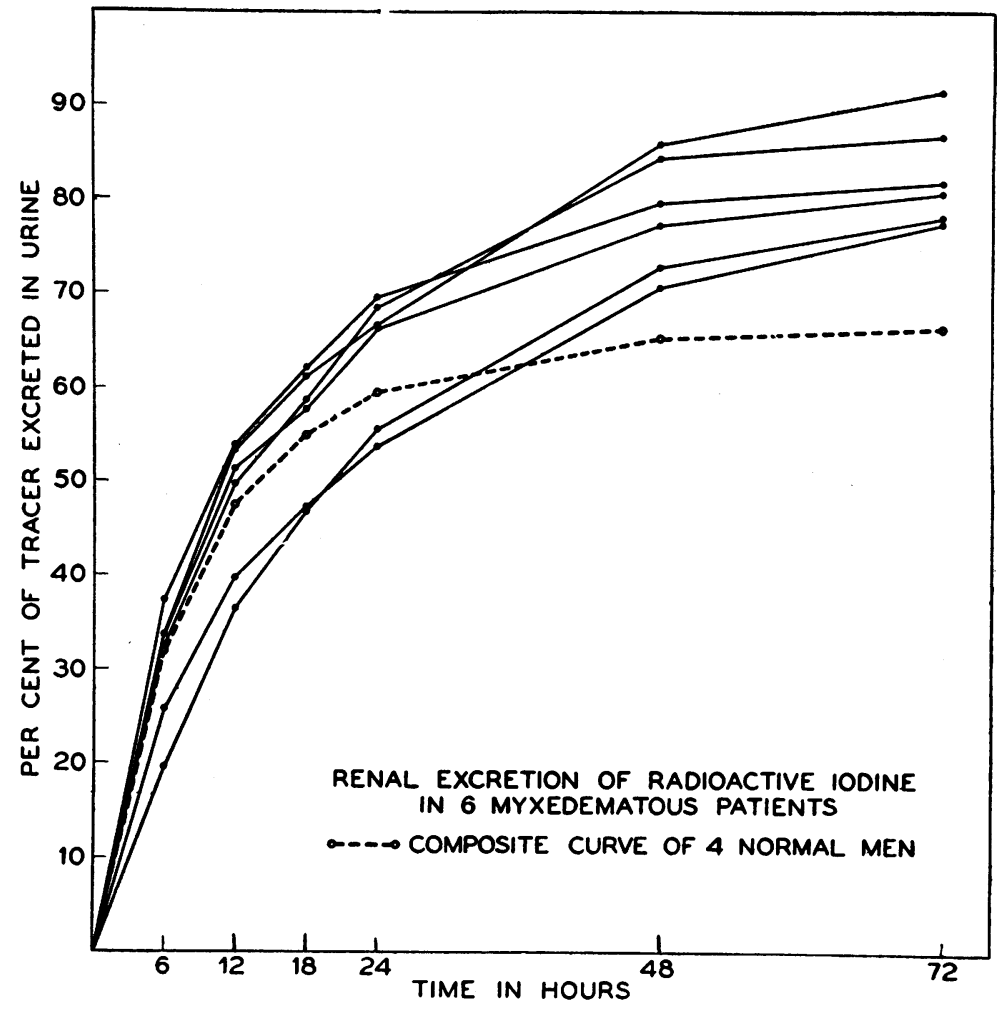

Fig. 3. Urinary Excretion of Radioiodine in 6 Patients Who Had MYXEDEMA

The composite curve of the normal men is included for comparison. Not only does more radioiodine appear in the urine in myxedema but a much longer time is required to reach a plateau.

curves describing excretion appear to become asymptotic very quickly, especially in the instances of very low iodine output. Closer inspection of these curves, however, indicates that a real plateau is not reached; instead iodine excretion continues at a slow and relatively constant rate after the rather short initial phase of relatively rapid excretion is completed. In this sense the hyperthyroid curves appear therefore to be diphasic; there is an initial phase which, like that of the normal subjects, appears exponential and a second phase which is linear. As will be pointed out later, this difference from normals is more apparent than real ; a linear phase is present in the normal curves also but is not apparent on casual inspection.

\section{ANALYSIS OF DATA}

The smoothness of the curves obtained, their exponential character and the variations encoun- tered in the different groups suggested that the differences between them might be expressed quantitatively by mathematical analysis. A series of equations has been found which appears to accomplish this goal adequately.

The urinary curves are quite well represented by the function

$$
Q=Q_{f}\left(1-e^{-r t}\right)
$$

where $Q$ is the amount of radioiodine, expressed as a fraction of the original dose, excreted in the urine in time $t ; Q_{f}$ is the asymptotic amount, that is, the total amount finally excreted, and $r$ is a constant depending on the rate of disappearance of iodine from the blood. The function thus is seen to have 2 parameters which define it: $r$ the rate constant, and $Q_{f}$ the final value of $Q$. The value of $r$ can be determined by plotting $\log \left(Q_{f}-Q\right)$ against $t$ (or the value of $Q_{f}-Q$ against $t$ on 


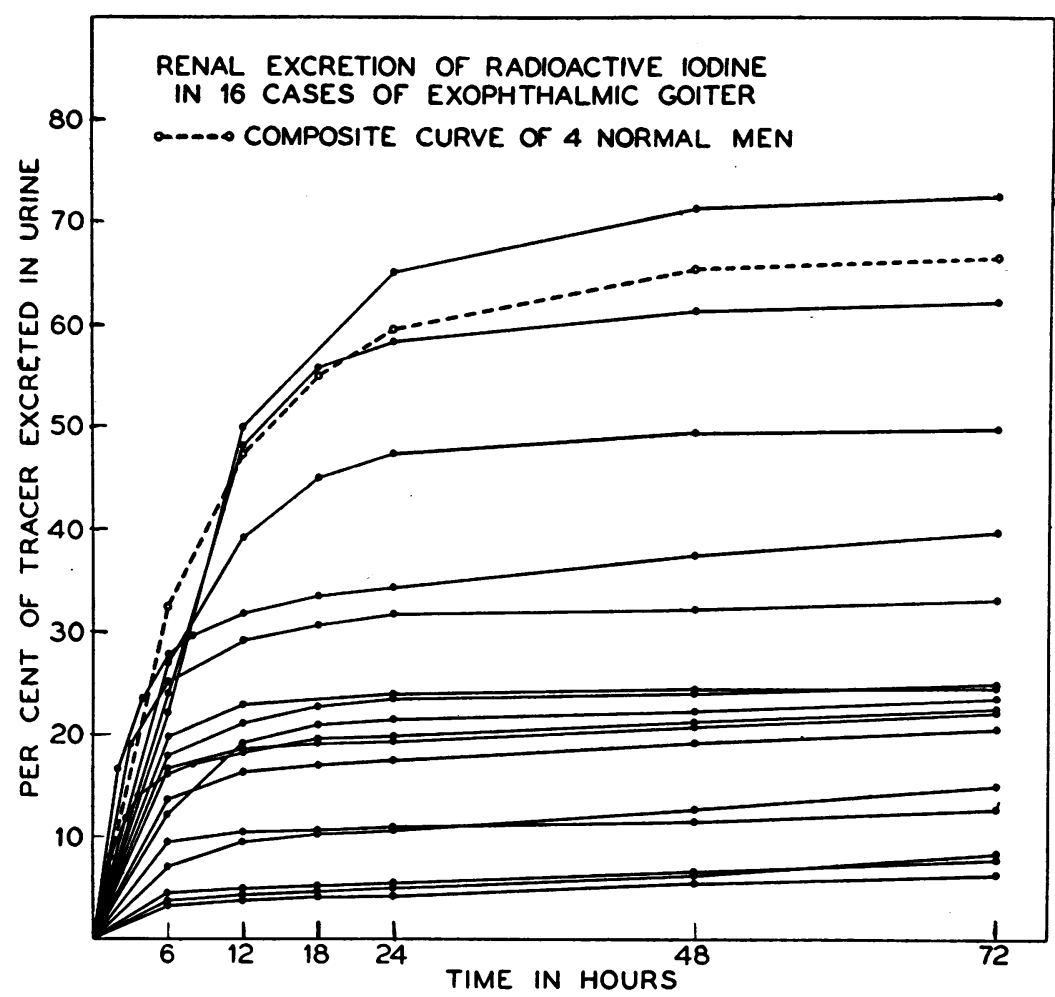

Fig. 4. Urinary Excretion of Radioiodine in 16 Cases of Untreated Exophthalmic GoITER

The cases varied widely in clinical severity, basal metabolic rates and excretion of radioiodine. Instead of reaching a plateau, a slow and relatively constant excretion of radioiodine persists after the initial period of rapid excretion.

semilogarithmic paper) and determining the slope of the straight line function which results. This necessitates a prior knowledge of $Q_{f}$. The value of $Q_{f}$ is estimated by inspection of the curve of the observed values $Q$ versus $t$, and adjusted so as to give a linear function for $\log \left(Q_{f}-Q\right)$ versus $t^{2}$

The proportional rate of removal of radioiodine from the blood by the kidneys and appearing as urinary radioiodine, is given by the product of $r$ by $Q_{f}$. The value $r$ itself is the proportional rate of disappearance of radioiodine from the blood into all tissues into which it goes. If therefore we assume for simplicity, and as a first approximation, that the iodine of the blood is going only to 2 tissues, the thyroid and the kidneys, the rate of absorption of iodine by the thyroid is given simply by the difference between the total rate and that

\footnotetext{
2 Detailed mathematical development and treatment will be given in a forthcoming publication.
}

estimated for the kidneys, that is, $r-r Q_{f}=r$ $\left(1-Q_{f}\right)$. This difference actually measures the rate of removal by all tissues together, other than the kidneys, and therefore, in so far as there are other tissues than thyroid involved, it does not give the true thyroid rate. However, inasmuch as variations in the disposal of iodine in the body to tissues other than the kidneys are likely to be due to variations in thyroidal absorption of iodine, the thyroid being the most important of these tissues, it seems reasonable to use the value $r$ ( 1 $Q_{f}$ ) as an index of the rate of removal of iodine by the thyroid. When the radioiodine curve of the thyroid can be accurately determined by observations obtained from the subject's thyroid directly, the rate of collection by the thyroid can be estimated.

It was noted in the preliminary discussion of the results that the excretion curves of the hyperthyroid group were diphasic and included a sec- 
ond phase in which excretion of iodine appeared to continue at a very low rate which was more or less constant or apparently linear. When curves of euthyroid patients are analyzed in the manner which has been described, it will be found that whenever the data have been collected for a sufficient time for the renal excretion curve to approach closely to the asymptote a similar nonexponential
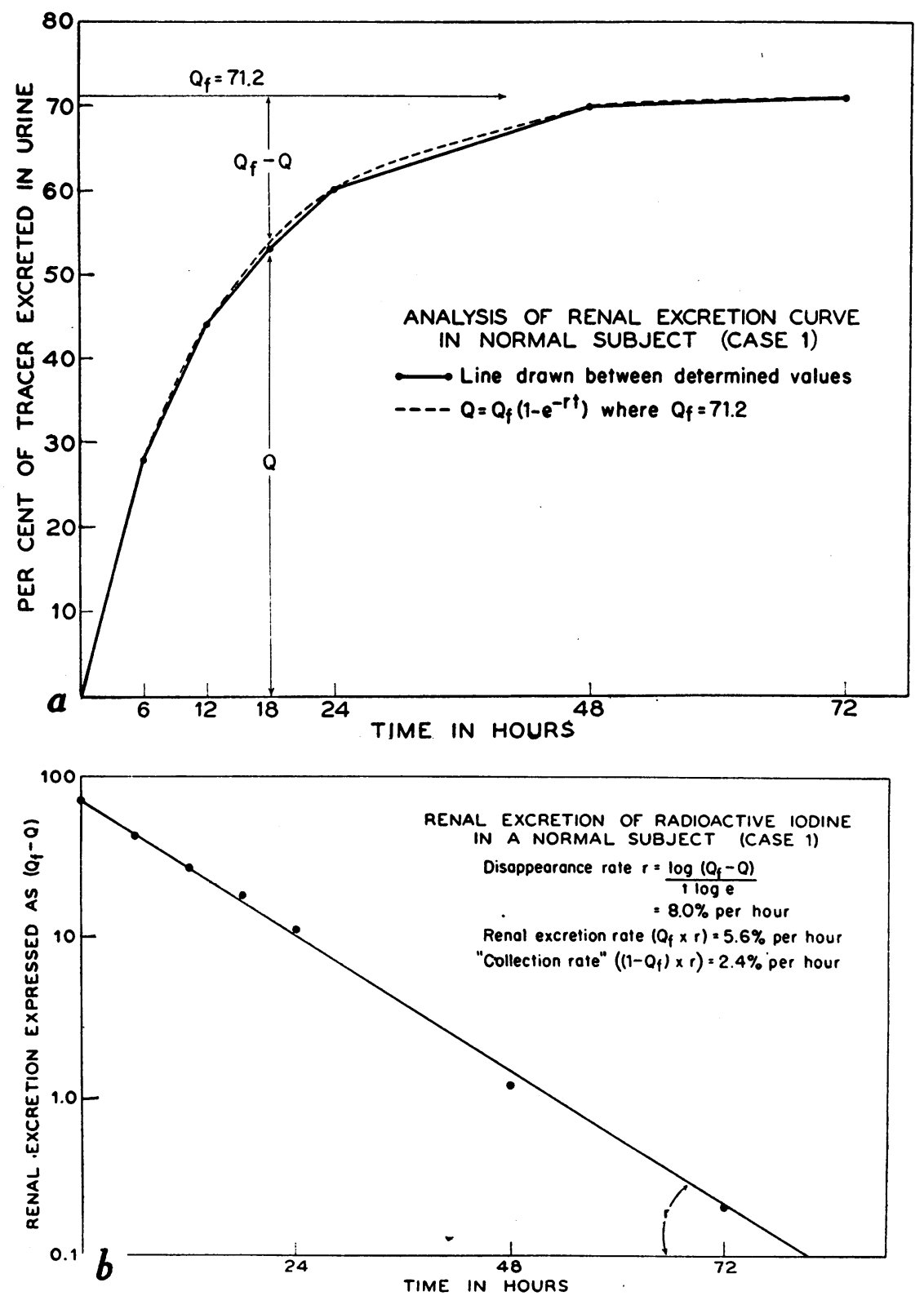

Fig. 5. Analysis of Urinary Excretion of Radioiodine in a Normal Subject

a. The quantities employed in analyzing the curve: $Q_{f}$ is the asymptote or plateau which the initial excretion curve approaches; the quantity $Q_{t}-Q$ may be plotted as a straight line on semilogarithmic paper.

b. The form of the renal excretion curve when plotted as the expression $Q_{f}-Q$. From the line the value $r$, or disappearance rate, may be determined. For the other constants which are derived see text. 
and apparently linear excretion of iodine above the asymptotic amount is encountered. The amount of this excess excretion, which for convenience has been defined as $a$ in the figures, is much less in the normal than in the hyperthyroid subjects. This quantity has not been detected in the hypothyroid excretion curves. However, since these approach the asymptote so slowly that, usually,
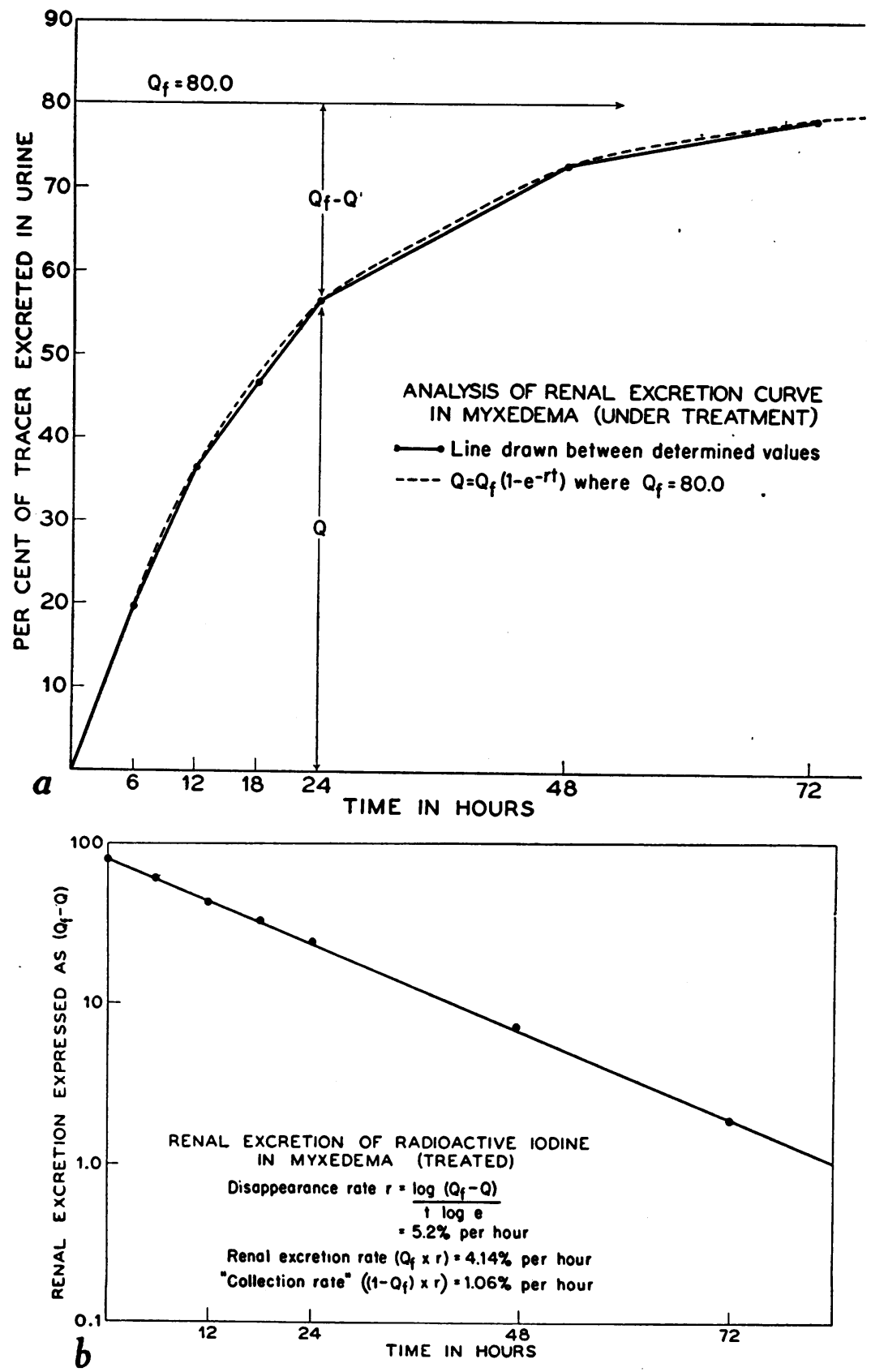

Fig. 6. Analysis of Urinary Excretion in a Case of Myxedema

a. Initial analysis of the curve. The asymptote may be determined even though the excretion curve does not reach a plateau in the time observed.

b. The form of the renal excretion curve when plotted as $Q_{f}-Q$. When the proper value for $Q_{r}$ is chosen, the points fit a straight line closely. 

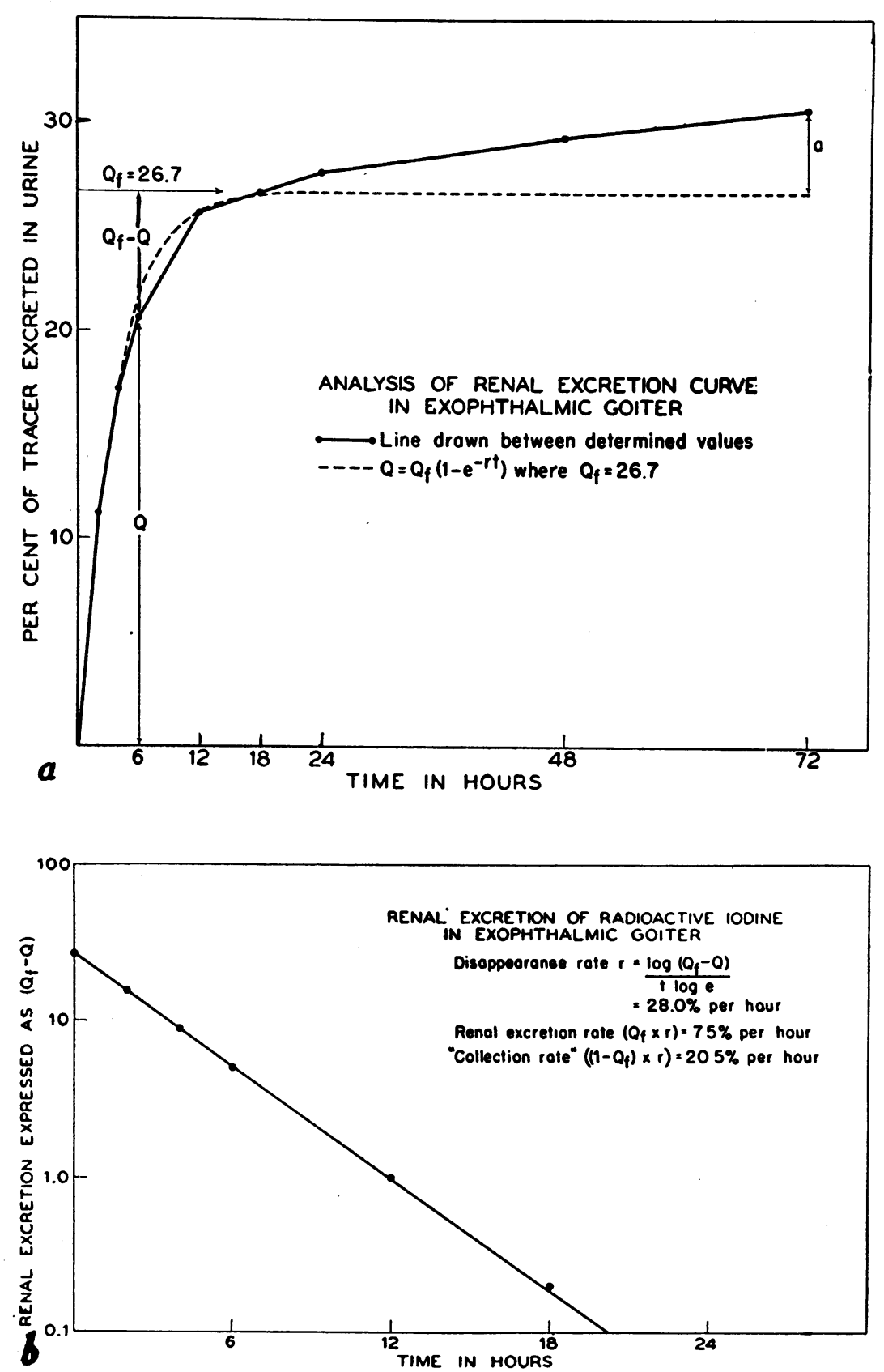

Fig. 7. Analysis of Urinary Excretion in a Case of Exophthalmic Gotrer

a. The initial analysis of the curve shows clearly that, instead of a plateau, the initial phase of excretion is followed by a fairly constant or linear phase. When observations on euthyroid subjects are continued long enough, the same phenomenon is encountered. The difference between the actual excretion of radioiodine in 72 hours and that which is predicted from extrapolation of the initial excretion curve is called the quantity $a$ for purposes of reference.

b. The initial renal excretion curve expressed as $Q_{f}-Q$. 
5 or 6 days are required to approach it closely and since the proportion of the dose remaining is very small by that time, it cannot be concluded with certainty that this quantity is not present in these curves. However, it does not appear to be present and its apparent absence may prove both correct and significant.

It is a hypothesis that the excess excretion of radioiodine referred to in the previous paragraph is related indirectly to the secretion of radioiodine previously stored in the thyroid. Preliminary measurements of radioiodine in blood and preliminary in vivo measurements make it clear that this excess excretion in urine does not reflect directly the secretion of stored radioiodine by the thyroid. However, secretion of radioiodine by the thyroid is generally assumed to be largely in the form of organically bound iodine. Perhaps therefore one should not expect an immediate and direct reflection in urinary excretion.

Figure $5 \mathrm{a}$ and $\mathrm{b}$ shows the analysis of the renal excretion curve for a normal subject; Figure 6a and $b$, for a myxedematous one, and Figure 7a and $b$, for a case of exophthalmic goiter. Practically all of the cases studied fit the straight line as closely as the examples given and the fact that the data fit the mathematical assumptions so precisely lends some support to the validity of such treatment.

According to the mathematical analysis which leads to the function presented for the radioiodine curve, the value $r$, whether determined from the radioiodine curve of the urine or by any other method, measures the proportional rate of disap-

TABLE I

Rate of disappearance of radioiodine

\begin{tabular}{|c|c|c|c|}
\hline \multirow{2}{*}{ Case } & \multirow{2}{*}{ Diagnosis } & \multicolumn{2}{|c|}{$\begin{array}{l}\text { Rate of disappearance } \\
\text { of radioiodine* }\end{array}$} \\
\hline & & Urine & Blood \\
\hline & & \multicolumn{2}{|c|}{ per cent per hour } \\
\hline $\begin{array}{l}1 \\
2 \\
3\end{array}$ & $\begin{array}{l}\text { Exophthalmic goiter } \\
\text { Exoph thalmic goiter } \\
\text { Adenomatous goiter with }\end{array}$ & $\begin{array}{r}27.3 \\
32.6 \\
9.7\end{array}$ & $\begin{array}{l}26.4 \\
31.4 \\
12.0\end{array}$ \\
\hline 4 & $\begin{array}{l}\text { Adenertnyroudism } \\
\text { hyperthyroidism }\end{array}$ & 12.9 & 12.4 \\
\hline
\end{tabular}

* The quantity $r$, or disappearance rate, determined from urinary excretion curves compared with the rate de termined from a series of blood samples obtained during the same period.
TABLE II

Rate of disappearance of radioiodine

\begin{tabular}{l|c}
\hline Source of calculation & $\begin{array}{c}\text { Rate of } \\
\text { disap- } \\
\text { pearance* }\end{array}$ \\
\hline Rer cent \\
Radioiodine in urine & $\begin{array}{c}\text { per hour } \\
\text { Radioiodine in blood }\end{array}$ \\
Radioactivity in thyroid, measured in vivo & 14.2 \\
Radioactivity in thigh, measured in vivo & 10.2 \\
& 11.9
\end{tabular}

* The quantity $r$, or disappearance rate, determined from 4 types of measurements in a normal subject following administration of a single tracer dose of radioiodine.

pearance of radioiodine from the blood. Accordingly, it should be the same value however determined. Table I shows the results obtained in 4 cases in which a comparison has been made between the value for $r$ determined from urinary data and the same quantity determined directly from blood samples, following the same tracer. The blood samples were drawn at intervals, digested with alkali and analyzed according to a technique which will be described elsewhere. The figures obtained from the 2 sources, blood and urine, agree very well. In Table II are values for disappearance rate, $r$, determined by 4 methods in a normal subject. The values for $r$ were calculated from serial measurements over the thyroid in vivo, serial measurements of peripheral radioactivity over the thigh in vivo, serial blood samples and the renal excretion curve. These figures also agree reasonably satisfactorily when one considers that the measurement of radioiodine in blood is somewhat less accurate than in urine and that the in vivo measurements, in their present stage of development, are only close approximations.

In Table III are given the means and standard deviations, for the 4 groups of cases comprising this study, of the following 4 quantities: (1) $Q_{f}$, which measures the fraction of radioiodine being excreted into the urine; (2) $r$, which measures the proportional rate of disappearance of radioiodine from the blood; (3) $r \times Q_{f}$, which measures the proportional rate of excretion into the urine and which will be referred to as the "renal excretion rate"; (4) $r\left(1-Q_{f}\right)$, which measures the proportional rate of absorption by other tissues than the kidneys (thyroid?) and which will be referred to as the "collection rate." In addition, the mean 
TABLE III

Summary of quantitative characteristics of renal excretion curves in various thyroid states

\begin{tabular}{|c|c|c|c|c|c|c|c|}
\hline Group & Condition & Cases & $\begin{array}{c}\text { Renal } \\
\text { fraction } \\
\left(Q_{f}\right)\end{array}$ & $\begin{array}{c}\text { Disappearance } \\
\text { rate } \\
(r)\end{array}$ & $\begin{array}{c}\text { Renal excretion } \\
\text { rate } \\
\left(r \times Q_{f}\right)\end{array}$ & $\begin{array}{l}\text { Collection } \\
\text { rate } \\
r(1-Q f)\end{array}$ & $\begin{array}{l}\text { Excess excretion } \\
\text { in } 72 \mathrm{hrs} . \\
(a) \dagger\end{array}$ \\
\hline & & & per cent of dose & \multicolumn{3}{|c|}{ per cent per hour } & per cent of dose \\
\hline $\begin{array}{l}1 \\
2\end{array}$ & $\begin{array}{l}\text { Normal conditions } \\
\text { Thyroid tumors } \\
\text { (euthyroid) }\end{array}$ & $\begin{array}{r}4 \\
10\end{array}$ & $\begin{array}{l}65.2 \pm 5.0^{*} \\
65.1 \pm 11.0\end{array}$ & $\begin{array}{r}11.1 \pm 3.6 \\
8.9 \pm 2.1\end{array}$ & $\begin{array}{l}7.2 \pm 2.1 \\
5.7 \pm 1.8\end{array}$ & $\begin{array}{l}3.9 \pm 2.8 \\
3.2 \pm 1.7\end{array}$ & $\begin{array}{l}1.4 \pm 1.4 \\
0.6 \pm 0.5\end{array}$ \\
\hline $\begin{array}{l}3 \\
4\end{array}$ & $\begin{array}{l}\text { Myxedema } \\
\text { Exophthalmic } \\
\text { goiter }\end{array}$ & $\begin{array}{r}6 \\
16\end{array}$ & $\begin{array}{l}84.6 \pm 4.5 \\
24.8 \pm 22.2\end{array}$ & $\begin{array}{r}6.8 \pm 1.8 \\
28.9 \pm 5.1\end{array}$ & $\begin{array}{l}5.8 \pm 1.4 \\
5.4 \pm 2.0\end{array}$ & $\begin{array}{r}1.0 \pm 0.6 \\
23.5 \pm 8.0\end{array}$ & $\begin{array}{c}0 \\
2.4 \pm 1.4\end{array}$ \\
\hline
\end{tabular}

* The mean of each group is given together with the standard deviation in order to indicate the relative variation encountered.

$\dagger$ The quantity $a$, which is also included, indicates the excess excretion of iodine in the urine after 72 hours. This expression does not attempt to define this factor quantitatively.

values of the excess excretion of radioiodine in urine, the quantity $a$, are included. The latter is expressed as the total excess after 72 hours. This is an admittedly inadequate means of expressing this quantity but it may serve until further study establishes its quantitative significance. The values as shown indicate the relative magnitude of the excess in the 4 groups of patients.

The variations in the renal fraction among the 4 groups of cases are what one would expect from inspection of the original excretion curves (Figures 1 to 4 , inclusive). The normals excreted an average of 65 per cent, the myxedematous patients conspicuously larger fractions and the hyperthyroid patients conspicuously smaller and more variable quantities.

The values for disappearance rate, $r$, show larger differences than do the renal fractions. The values for hypothyroid subjects are significantly lower than for the normals and the values for hyperthyroid subjects are more than $2 \frac{1}{2}$ times as high as those for the normals.

The renal excretion rates $\left(r \times Q_{f}\right)$ vary considerably from patient to patient and the variations are of sufficient order to account for some of the variations of iodine collection which are observed. However, no significant difference exists in the mean renal excretion rates of the 4 groups and all show approximately the same degree of individual variation. One might expect to find reduced renal excretion of significant degree in hypothyroidism. This point will have to be settled by study of a larger series of untreated patients.

The most striking differences are found in the values for collection rates, $r\left(1-Q_{f}\right)$. The hy- pothyroid subjects show, as one would expect, exceedingly low collection rates, 0.6 to 1.6 per cent per hour. What proportion of this represents loss in feces and sweat, what proportion errors in the method, and what proportion actual collection by the thyroid or peripheral tissues it is impossible to say. The very high collection rates found in the cases of exophthalmic goiter may be regarded as due to variations of thyroid function, even though thyroid function is not here being measured directly. The mean collection rates in exophthalmic goiter were 6 times the normal rates whereas the renal fractions as such were less than half the normal values.

\section{COMMENT}

It is reasonable to assume that substantially all, if not quite all, of the radioiodine given as a tracer is either excreted in the urine or collected by the thyroid. The fraction of the total amount of iodine disappearing from the blood which is collected by the thyroid is therefore a relative quantity, depending on the function of the kidneys as well as the function of the thyroid itself. Even if the thyroid function with respect to iodine collection remains quite constant, a variation in function of the kidneys (or other iodine-collecting tissue) with respect to iodine collection will alter the picture of collection of iodine by the thyroid. Thus, if the function of the kidneys is altered so that the renal collection rate is lowered, the amount of iodine collected in any given time by the thyroid will increase, as will also the total amount of iodine eventually collected by the thyroid.

The following hypothetical case will illustrate 
this point: If the thyroid-collecting rate was 3 per cent per hour and the renal excretion rate 5 per cent, the thyroid would collect in the first 24 hours 32 per cent of the original dose and asymptotically it would collect 37.5 per cent of the dose. If now the thyroid rate remained at 3 per cent but the renal excretion rate was reduced to 1 per cent, the thyroid would collect in the first 24 hours 46.1 per cent of the original dose and asymptotically 75.0 per cent. Attention only to the amounts of iodine collected by the thyroid might therefore easily give the impression that the thyroid function had been altered. Use of the formulae presented earlier in this paper would avoid this erroneous conclusion, for what remains constant in the situation of unaltered thyroid function is the product of $r$ and $Q_{f}$, which for the situation before the alteration of the renal function would be $0.375 \times$ $0.08=0.03$ and after the alteration of the renal function would still be $0.75 \times 0.04=0.03$. The method of study which has been described suggests a means for determining the capacity of the kidneys to excrete iodine without regard to thyroid function and of the thyroid to collect iodine without regard to variations of renal function.

Tracers are ordinarily considered as labeling a specific quantity of iodine so as to make its behavior distinct from that of the material with which it is mixed. It is also true, however, that once a radioiodine tracer is mixed with the circulating iodide of the blood (either after complete absorption of an oral dose or after intravenous administration) it may be regarded as a label temporarily, not only of the tracer dose, but also of all of the iodide in circulation in the blood and in the body fluids which are in osmotic equilibrium with the blood. In this sense whatever happens to the tracer is a valid quantitative measure of what is happening to the circulating iodide, since the two behave identically. The quantities which have been proposed, therefore, express the percentage of the total circulating blood iodide which is being excreted or otherwise disposed of, as well as the percentage of the tracer which is disappearing. This does not necessarily imply that the circulating iodide in the blood is constant in amount. It merely implies that whatever the range of variation of circulating iodide in blood at the time of observation, the renal excretion rate and the col- lection rate (expressed as a percentage of the total quantity) are relatively constant quantities.

The radioiodine tracers which have been studied previously, as well as those described in the present study, have all been given orally. This raises the question whether the time required for absorption affects the results significantly. Preliminary observations suggest that absorption time has not been a critical factor in the majority of instances. However, a comparative study of intravenous versus oral tracers is in progress in order to elucidate this point more fully.

Hamilton, (18), in an early paper, described the remarkable speed with which an oral dose of radioiodine appeared in the blood. Using a Geiger-Müller counter over the hand as an indicator, he found the absorption was 80 per cent complete in an hour. In some preliminary studies we have found that in both normal and hyperthyroid subjects, absorption may be complete in an hour or less. Because the absorption from the gastro-intestinal tract is complete within such a short period it appears reasonable at the moment to assume that, in most instances, only a small error will result from ignoring it. There is some suggestion that the presence of food in the stomach may somewhat prolong absorption of radioiodine and on this account we have made it a practice to give tracers to patients in the fasting state.

It is obvious that sooner or later the iodine collected and stored in the thyroid is likely to be secreted from the gland. If one excepts the observations made by Hamilton and Soley and their associates (14) of the behavior of very large doses of labeled iodide in toxic goiters and in hypothyroid children with goiter, subsequent secretion of radioiodine by the thyroid appears to occur much more slowly than its initial collection. So long as it takes place relatively slowly, thyroidal secretion will not modify the exponential character of the initial collection or excretion curves until either is approaching an asymptotic level. Studies of the quantitative character of the subsequent secretion of radioiodine by the thyroid may as a matter of fact prove far more significant than collection studies. However, because of artefacts resulting from the quantity of radiation in the 
tracer, they may be subject to more uncertainty than are the studies of collection rates.

The quantity of radiation employed in all tracer studies which have so far been reported substantially exceeds in the thyroid the arbitrary tolerance dose of 0.1 roentgen per day which is approved for total body radiation of persons working with radium or roentgen rays. Considering the great concentrating power of the thyroid, doses of $I^{131}$ of the order of 1 or 2 microcuries would have to be used in order to keep the radiation exposure of the thyroid below 0.1 equivalent roentgen per day. Such minute tracers are not practicable with present methods. The radiation dosage in the present study, assuming the dose employed to be 200 microcuries of $\mathrm{I}^{\mathbf{1 3 1}}$, is of the order of 20 equivalent roentgens per day or a total integrated dose per patient of around 230 equivalent roentgens. No information is available regarding the minimal quantity of radiation per day which is capable of inducing biologic effects in the thyroid either within a few hours or within a period defined by a few half lives of $\mathrm{I}^{131}$. Until this is known the possibility must always be considered that the radiation resulting from tracer doses of the magnitude employed may produce biologic effects which influence the results observed.

Another factor of importance in the evaluation of tracer studies is the quantity of carrier, or inert iodide, which is given with the radioiodine. The comparison by Hamilton and Soley of the difference in response to a 14-mgm. dose of sodium iodide compared with a dose of 0.1 microgram leaves no doubt that the size of the carrier can modify the result obtained. For most purposes it is desirable that the quantity given in a tracer be an insignificant amount or at most a small increment to the iodide already present in the body. We have so far avoided very small tracers (1.0 microgram or less) because of the fear, perhaps unfounded, that excessive losses will occur with such tiny quantities because of adherence to containers and so forth. If one assumes blood iodide to be in osmotic equilibrium with the extracellular fluid, as it probably is, the carrier which we have employed, 100 micrograms, should represent an average increment of the order of 1 microgram of sodium iodide per $100 \mathrm{cc}$. of plasma. Before it can be said with certainty that this is an incre- ment which does not of itself modify iodine metabolism more detailed studies with varying quantities of carrier will be needed.

\section{SUMMARY}

The urinary excretion of radioiodine following its oral administration has been studied in normal subjects, euthyroid patients who had low-grade thyroid malignant lesions, patients who had myxedema and patients who had untreated exophthalmic goiter.

The urinary excretion curves differ significantly among the euthyroid, hypothyroid and hyperthyroid groups. Mathematical analysis of the urinary excretion yields the following 4 quantities: (1) the renal fraction (which is the fraction of the dose of radioiodine primarily excreted in the urine); (2) the disappearance rate (which is the proportional rate of disappearance of radioiodine from the blood) ; (3) the renal excretion rate (which is the proportional rate of excretion into the urine); and (4) the collection rate (which measures the proportional rate of disappearance into other sites than the kidneys). In so far as the thyroid represents the chief site in the body for collecting iodine, the last of these 4 values serves as an index of thyroid-collection rate. When the radioiodine curve of the thyroid can be determined by observations obtained from the subject's thyroid directly, the true rate of collection by the thyroid can be estimated.

Estimations of disappearance rate, based on analysis of renal excretion, have been found to agree fairly closely with estimations of the same quantity based on direct measurements of blood samples, measurements of the thyroid in vivo and measurements of peripheral radioactivity in vivo.

The renal fraction is greater than normal in hypothyroid patients and is less than normal in hyperthyroid patients. The disappearance rate is less in hypothyroid patients than in normal subjects and is markedly greater than normal in cases of hyperthyroidism. Significant individual variations occur in renal excretion rates but no significant differences were observed in the mean renal excretion rates among the 4 groups of cases studied. The most significant variation observed occurred in the collection rates, which were very much less than normal in the hypothyroid cases, 
and averaged 6 times the normal in the hyperthyroid patients.

The significance, the limitations and the possibilities of this technique have been discussed.

\section{BIBLIOGRAPHY}

1. Hertz, S., Roberts, A., and Evans, R. D., Radioactive iodine as indicator in study of thyroid physiology. Proc. Soc. Exper. Biol. \& Med., 1938, 38, 510.

2. Hertz, S., Radioactive iodine as an indicator in thyroid physiology; observations on rabbits and on goiter patients. Am. J. Roentgenol., 1941, 46, 467.

3. Hertz, S., Roberts, A., and Salter, W. T., Radioactive iodine as an indicator in thyroid physiology. IV. The metabolism of 'iodine in Graves' disease. J. Clin. Invest., 1942, 21, 25.

4. Keating, F. R., Jr., Rawson, R. W., Peacock, W., and Evans, R. D., The collection and loss of radioactive iodine compared with the anatomic changes induced in the thyroid of the chick by the injection of thyrotropic hormone. Endocrinology, 1945, 36, 137.

5. Larson, R. A., Keating, F. R., Jr., Peacock, W., and Rawson, R. W., The effect of thiouracil on the collection of radioactive iodine by the thyroid of the chick. Endocrinology, 1945, 36, 160.

6. Leblond, C. P., and Süe, P., Iodine fixation in the thyroid as influenced by the hypophysis and other factors. Am. J. Physiol., 1941, 134, 549.

7. Leblond, C. P., Fertman, M. B., Puppel, I. D., and Curtis, G. M., Radioiodine autography in studies of human goiterous thyroid glands. Arch. Path. 1946, 41, 510.

8. Leiter, L., Seidlin, S. M., Marinelli, L. D., and Baumann, E. J., Adenocarcinoma of the thyroid with hyperthyroidism and functional metastases. I. Studies with thiouracil and radio-iodine. J. Clin. Endocrinol., 1946, 6, 247.
9. Perlman, I., Morton, M. E., and Chaikoff, I. L., Radioactive iodine as an indicator of the metabolism of iodine. II. The rates of formation of thyroxine and diiodotyrosine by the intact normal thyroid gland. J. Biol. Chem., 1941, 139, 449.

10. Franklin, A. L., Chaikoff, I. L., and Lerner, S. R., The influence of goitrogenic substances on the conversion in vitro of inorganic iodide to thyroxine and diiodotyrosine by thyroid tissue with radioactive iodine as indicator. J. Biol. Chem., 1944, 153, 151.

11. Rawson, R. W., Tannheimer, J. F., and Peacock, W., Uptake of radioactive iodine by thyroids of rats made goiterous by potassium thiocyanate and by thiouracil. Endocrinology, 1944, 34, 245.

12. Hamilton, J. G., and Soley, M. H., Studies in iodine metabolism by the use of a new radioactive isotope of iodine. Am. J. Physiol., 1939, 127, 557.

13. Hamilton, J. G., and Soley, M. H., Studies in iodine metabolism of thyroid gland in situ by use of radio-iodine in normal subjects and in patients with various types of goiter. Am. J. Physiol., 1940, 131, 135.

14. Hamilton, J. G., Soley, M. H., Reilly, W. A., and Eichorn, K. B., Radioactive iodine studies in childhood hypothyroidism. Am. J. Dis. Child., 1943, 66, 495.

15. Rawson, R. W., Hertz, S., and Means, J. H., Thiocyanate goiter in man. Ann. Int. Med., 1943, 19, 829.

16. Rawson, R. W., Evans, R. D., Means, J. H., Peacock, W. C., Lerman, J., and Cortell, R. E., The action of thiouracil upon the thyroid gland in Graves' disease. J. Clin. Endocrinol., 1944, 4, 1.

17. Seidlin, S. M., Marinelli, L. D., and Oshry, Eleanor, Radioactive iodine therapy; effect on functioning metastases of adenocarcinoma of the thyroid. J. A. M. A., 1946, 132, 838.

18. Hamilton, J. G., The rates of absorption of the radioactive isotopes of sodium, potassium, chlorine, bromine, and iodine in normal human subjects. Am. J. Physiol., 1938, 124, 667. 